NASA

Technical Memorandum 103637
AVSCOM

Technical Memorandum 90-C-014

\title{
Axial-Torsional Fatigue: A Study of Tubular Specimen Thickness Effects
}

Peter J. Bonacuse

Propulsion Directorate

U.S. Army Aviation Systems Command

NASA Lewis Research Center

Cleveland, Ohio

and

Sreeramesh Kalluri

Sverdrup Technology, Inc.

NASA Lewis Research Center Group

Brook Park, Ohio

December 1990 
AXIAL-TORSIONAL FATIGUE:

\title{
A STUDY OF TUBULAR SPECIMEN THICKNESS EFFECTS
}

\author{
Peter J. Bonacuse \\ Propulsion Directorate \\ U.S. Army Aviation Systems Command \\ NASA Lewis Research Center \\ Cleveland, Ohio 44135 \\ and \\ Sreeramesh Kalluri \\ Sverdrup Technology, Inc. \\ NASA Lewis Research Center Group \\ Brook Park, Ohio 44142
}

\begin{abstract}
SUMMARY
A room-temperature experimental program was conducted on AISI type 316 stainless steel to determine the effect of wall thickness on the cyclic deformation behavior and fatigue life of thin-wall, tubular, axial-torsional fatigue specimens. The following experimental variables were examined in this study: the depth of the surface work-hardened layer produced in specimen machining, and the effects of strain range and axial-torsional strain phasing. Tubular fatigue specimens were fabricated with wall thicknesses of $1.5,2.0$, and $2.5 \mathrm{~mm}$. One as-fabricated specimen from each wall thickness was sectioned for microstructural examination and microhardness measurement. A specimen of each wall thickness was tested at each of three conditions - high strain range in-phase, low strain range in-phase, and low strain range out-of-phase - for a total of nine axial-torsional fatigue experiments. The machining-induced workhardened zone, as a percentage of the gage section material, was found to have a minimal effect on both deformation behavior and fatigue life. Also, little or no variation in fatigue life or deformation behavior as a function of wall thickness was observed. Out-of-phase fatigue tests displayed shorter fatigue lives and more cyclic hardening than in-phase tests.
\end{abstract}

\section{INTRODUCTION}

A round-robin program, organized by the fatigue committee of ASTM, was conducted during 1987-88 to determine the extent of variability in fatigue data generated by laboratories that perform axial-torsional fatigue testing. 1 Each laboratory was required to perform two in-phase axial-torsional fatigue tests on AISI type 304 stainless steel at room temperature. Although all the material used in the round-robin program came from the same heat, the choice of the tubular specimen geometry and the responsibility of specimen fabrication were left to the individual laboratories. The wall thicknesses of the tubular specimens used in the round-robin program varied from 1.5 to $3.0 \mathrm{~mm}$. The results

1Personal communication with P. Kurath of University of Illinois at Urbana-Champaign, Urbana, Illinois. 
of the round-robin program agreed to within a factor of 2 on fatigue life but displayed variations in cyclic deformation behavior from one laboratory to another. These variations seemed to indicate a correlation between the cyclic deformation behavior and the specimen wall thickness. The program described in this report controlled some of the test variables in an attempt to verify this correlation and quantify its effects. Tubular specimens of a material (AISI type 316 stainless steel) similar to that used in the round-robin program (AISI type 304 stainless steel) were fabricated in three wall thicknesses with equal gage section outer diameters. These specimens were then tested in in-phase and out-of-phase axial-torsional fatigue at two strain ranges, and the cyclic deformation behavior and fatigue lives were recorded.

Initially, one possible cause of the variations in cyclic deformation behavior observed in the round-robin program was thought to be work-hardened material on the inner and outer surfaces of the specimen. It follows that if the depth of the surface work-hardened zone (usually found in any machined surface) is constant, a thinner specimen wall would have a larger percentage of gage section material in a work-hardened condition. If this were indeed the case, it would explain the cyclic strain hardening behavior observed in the AISI type 304 stainless steel (304 SS) round-robin program. Pursuing this hypothesis, microhardness measurements were taken on as-machined, sectioned AISI type 316 stainless steel (316 SS) specimens of all three wall thicknesses. Even though the fabrication requirements for the specimens were designed to minimize surface work hardening, significant surface hardening was observed.

The cyclic deformation behavior and fatigue lives of 316 SS obtained under in-phase and out-of-phase axial-torsional conditions for tubular specimens in three different wall thicknesses are presented in this report.

\section{EXPERIMENTAL PROCEDURE}

In this section, details of specimen preparation, test equipment, and the procedures used to perform the tests are discussed.

\section{Specimen Preparation}

Specimens were fabricated from a single heat of commercial grade 316 SS, 50.8-mm-o.d. barstock. The chemical composition and the room-temperature tensile properties reported by the manufacturer are shown in table I. The as-received microstructure of the $316 \mathrm{SS}$ is shown in figure 1 . The grains in this material were equiaxed and had an ASTM grain size of 6 to 6.5 (approximately $40 \mu \mathrm{m}$ ).

Specific instructions for specimen fabrication and preparation of both the inner and outer surfaces of the specimen gage section were given to the machinist. A diagram of the specimen geometry and a list of the specimen fabrication instructions are included in figure 2. The extra care in surface preparation was specified to minimize the effect of surface finish on the test results and to prevent crack nucleation and growth from the inner surface of the specimen. Upon receiving the specimens from the manufacturer, in-house inspection of the inner surfaces was performed. All measurements showed that roughness average values $\mathrm{R}_{\mathrm{a}}$ were less than $0.2 \mu \mathrm{m}$. 
A total of 12 specimens were fabricated for this program; four specimens in each of three wall thicknesses: $1.5,2.0$, and $2.5 \mathrm{~mm}$. One specimen in each wall thickness was used to examine the extent of work hardening in the machined surface material. These specimens were sectioned (fig. 3), polished, and etched to reveal the material microstructure. Vickers diamond point microhardness measurements (with a mass of $500 \mathrm{~g}$ ) were then taken within $100 \mu \mathrm{m}$ of the inner and outer surfaces and near the mid-section. The microhardness measurements were acquired at each location, and an average hardness was calculated. Care was taken to place the indentations within individual grains. The results of these measurements are shown in figure 4 .

\section{Test Equipment}

An axial-torsional load frame with an axial load capacity of $225 \mathrm{kN}$ and a torque capacity of $2.25 \mathrm{kN}-\mathrm{m}$ was used in the program. The strain-measuring device used was a commercial axial-torsional extensometer. The closed-loop control was provided by two servocontrollers that were in turn connected to a 16-bit minicomputer. All tests were run in strain control with the minicomputer providing the strain waveforms and simultaneously recording load, strain, and stroke data at logarithmic intervals from the axial and torsional transducers. Further detail on the test equipment can be found in references 1 and 2 .

\section{Test Procedures}

Before each fatigue test was started, axial and shear elastic moduli were determined according to the procedure described in reference 2 . These values were recorded for subsequent analysis and to confirm that the test system was working properly.

The test matrix for this program is shown in table II. A total of nine fatigue tests were performed. These tests included six in-phase tests at two strain ranges and three $90^{\circ}$ out-of-phase tests (one test of each type was performed on a specimen of each wall thickness). All testing was performed under strain control at room temperature in air. The frequency of the strain waveforms was $0.1 \mathrm{~Hz}$. A schematic of the waveforms for in-phase and out-of-phase tests is shown in figure 5 . The failure definition for all tests was a 25-percent dropoff (referenced to the last cycle during which data were recorded) in either the axial or the torsional peak loads. Because the crack orientation and location for each test could not be predicted with any certainty, the 25-percent load dropoff was employed as an estimate of the crack initiation life. Several tests were shutdown by electronic limits set on the transducer outputs somewhat before a 25-percent load dropoff was encountered. Upon inspection, all specimens from these tests were found to contain a large (2 to $4 \mathrm{~cm}$ ) crack. All cracks that led to failure in the specimens originated at the outer surface and propagated into and along that surface. For the outof-phase tests the axial strain was ramped up by the software to the initial phase angle before the fatigue test was started. For further details on the testing procedure and software used, consult references 1 and 2 . 


\section{RESULTS}

The first goal of this study was to determine if there was a correlation between the measured hardness in the gage section and the thickness of the specimen wall. In the 304 SS round-robin program discussed previously, as-received specimens displayed significant work hardening (measured by Knoop's diamond point indenter) in the surface layers of the gage section (ref. 1). The material near the inner surface of the gage section was as much as 45 percent harder than "virgin" material in the grip section. It is thought that this hardening was caused by the stresses imposed on the surface material during the machining process. It was also observed that the interior of the gage section was harder than the interior of the grip section. This suggested that some mechanism had preferentially hardened the material through the thickness of the gage section as well. The 316 SS specimens tested in this study also exhibited machining-induced surface work hardening (fig. 4). The depth of the work-hardened zone was about two to three grains (approximately $120 \mu \mathrm{m}$ ) into the surface of the specimen. There was, however, no preferential throughthickness hardening of the gage section; in fact, the average hardness of the gage section was lower than that of the grip material. There were also no significant differences in the average gage section microhardnesses for the three tubular specimen wall thicknesses examined.

The second goal was to determine if the cyclic deformation behavior of the material was dependent on the wall thickness (or percentage of workhardened material due to machining). The test control software used the inner and outer radii of each specimen to calculate the cross-sectional area and the torsional moment of inertia. These computed values were then used to calculate the appropriate stress values at the mean radius of the specimen. The axial and shear stress ranges versus the number of cycles for the fatigue tests conducted in this study are shown in figure 6. The axial and torsional hysteresis loops for the in-phase and out-of-phase experiments are depicted in figure 7 . The figures show no significant correlation between the cyclic deformation behavior of the specimens and their wall thickness. The small differences that can be observed do not always correlate with the wall thickness. This seems to imply that the depth of surface work hardening as a proportion of the total wall thickness has no significant effect on the initial and subsequent deformation behavior of the specimen for the geometries and loading conditions considered.

The average Young's and shear moduli for the 316 SS specimens in this study were 195.3 and $77.7 \mathrm{GPa}$, respectively. The standard deviations in the Young's and shear moduli $(0.7$ and $1.0 \mathrm{GPa})$ were relatively small. The recorded axial and torsional moduli for all tests exhibited a maximum deviation that was within 2.3 percent of the mean moduli. The average elastic Poisson's ratio, calculated by assuming an isotropic material from the average elastic and shear moduli, was 0.257 . Also, a statistical analysis revealed no significant correlation between the specimen wall thickness and the experimentally determined elastic properties.

A third, ancillary, goal of this study was to investigate the effect of a shift in phase between the axial and torsional strain waveforms on the fatigue and deformation behavior of 316 SS. As can be seen in figures 6 and 7 , for similar axial and torsional strain ranges the cyclic deformation behavior of the in-phase tests is significantly different from that of the out-of-phase tests. At the beginning of a fatigue test the out-of-phase tests had much 
higher axial and torsional stress ranges than the in-phase tests. The out-ofphase tests also tended to show less cyclic softening over the course of the test. The out-of-phase cyclic hardening behavior observed in this study agrees with published work on the axial-torsional deformation behavior of 316 SS (ref. 3). It is interesting to note that, at less than half the strain range, the out-of-phase experiments (fig. 6(b)) exhibited higher stress ranges than the in-phase experiments (fig. 6(c)). Two fatigued specimens were sectioned and examined: a specimen tested under in-phase loading (SS316-1), and a specimen tested under out-of-phase loading (SS316-2). Sections of the gage section were mounted, polished, and etched with chromic acid. Micrographs of the gage section surfaces are shown in figures 8 and 9 . The micrograph of the in-phase tests shows persistent slip band formation oriented along planes of maximum shear (i.e., $-30^{\circ}$ and $60^{\circ}$ to the specimen axis). The micrograph of the out-ofphase tests, however, shows a more random orientation of slip bands. Jayaraman and Ditmars (ref. 4) used this multiple-slip phenomenon to explain the accelerated hardening in high-strain, out-of-phase tests. Our data would tend to corroborate this conclusion.

The equivalent strain range is plotted against the observed cyclic life for in-phase and out-of-phase axial-torsional fatigue tests in figure 10 . A value for Poisson's ratio must be chosen to compute the equivalent strain range. The following equation was used to compute the effective Poisson's ratio, veff, for each specimen by using only the axial material response at half-life:

$$
\nu_{\text {eff }}=\left(\frac{\Delta \varepsilon_{\text {el }}}{\Delta \varepsilon_{\text {tot }}}\right) \nu_{\text {el }}+\left(\frac{\Delta \varepsilon_{\text {pl }}}{\Delta \varepsilon_{\text {tot }}}\right) \nu_{\text {pl }}
$$

where $\nu_{\text {el }}$ is the average elastic Poisson's ratio, $\nu_{\mathrm{pl}}=0.5$ is the plastic Poisson's ratio, $\Delta \varepsilon_{e l}$ is the elastic strain range (the measured axial stress range divided by the average measured elastic modulus), and $\Delta \varepsilon_{p} l$ is the plastic strain range (the total strain range $\Delta \varepsilon_{\text {tot }}$ minus the elastic strain range). The fatigue lives observed in the out-of-phase experiments were on the order of five times lower than the corresponding fatigue lives of the in-phase experiments.

\section{DISCUSSION}

The microhardness testing done on the as received specimens showed no statistically significant variation in the hardness measurements at all three of the examined gage section locations. A Student's $t$ test (a statistical test for determining if two samples come from the same population) was performed to compare the means of the 10 microhardness measurements taken at each location on the 1.5- and 2.5-mm-thick specimens. A 95-percent confidence interval was chosen and a pooled variance was used. At every location but at the outer gage section surface the hypothesis that all samples came from the same population could not be rejected.

The grip section of each specimen was significantly harder than the gage section. This could be due to the hardened state of the outer part of the bar that might have been induced when the barstock was extruded. The heat treatment described by the manufacturer (table I) may not have been sufficient to 
fully anneal the material. The reported values of yield strength $\sigma_{\mathrm{y}}$ and ultimate tensile strength $\sigma_{u t s}$ for this heat of 316 SS (table I, 520 and $660 \mathrm{MPa})$ are significantly higher than those reported in the open literature (ref. 5, 255 and $565 \mathrm{MPa}$ ).

The results of the 304 SS round-robin program suggested that there might be some correlation between the specimen wall thickness and the cyclic deformation behavior. However, the study discussed in this report disproves this hypothesis. There are, however, other test variables that were not considered in this study which could have contributed to the variation in cyclic deformation behavior in the round-robin program. These test variables include, but are not limited to, strain measurement techniques and transducer calibration practices used by the participating laboratories.

\section{CONCLUSIONS}

Axial-torsional fatigue tests on 316 SS showed that the wall thickness (in the range of wall thicknesses tested) had little or no effect on the deformation behavior or fatigue life of this material.

The correlation between deformation behavior and wall thickness observed in the 304 SS, axial-torsional, round-robin program is more likely due to other test variables, such as the differences in strain measurement techniques and transducer calibration practices, than to work hardening of the specimens during fabrication.

Although no statistically significant variation in average hardness was observed among the tubular specimens of three different wall thicknesses, all of the examined specimens showed significant surface work hardening. However, this hardened surface condition seems to have had no effect on the material's deformation response and fatigue life.

During the in-phase axial-torsional fatigue tests, 316 SS exhibited cyclic softening; whereas during the out-of-phase tests it exhibited much higher hardening at the beginning of the test and significantly less cyclic softening over the course of the test. The excessive hardening in the out-of-phase tests is attributable to slip in multiple directions within individual grains of the material. In addition, the cyclic lives under out-of-phase conditions were lower by about a factor of 5 than the cyclic lives under in-phase axialtorsional loading conditions.

\section{REFERENCES}

1. Bonacuse, P.J.; and Kalluri, S.: Results of Inphase Axial-Torsional Fatigue Experiments on 304 Stainless Steel. NASA TM-101464, AVSCOM-TR-88-C-022, 1989.

2. Kalluri, S.; and Bonacuse, P.J.: A Data Acquisition and Control Program for Axial-Torsional Fatigue Testing. Applications of Automation Technology to Fatigue and Fracture Testing, ASTM STP 1092, A.A. Braun, N.E. Ashbaugh and F.M. Smith Eds., American Society for Testing and Materials, Philadelphia, 1990, pp. 269-287. 
3. Benallal, A.; and Marquis, D.: Constitutive Equations for Nonproportional Cyclic Elasto-Viscoplasticity. J. Eng. Mater. Technol., vol. 109, no. 4, 0ct. 1987, pp. 326-336.

4. Jayaraman, N.; and Ditmars, M. M.: Torsional and Biaxial (TensionTorsion) Fatigue Damage Mechanisms in Waspaloy at Room Temperature. Int. J. Fatigue, vol. 11, Sept. 1989, pp. 309-318.

5. Conway, J.B.; Stentz, R.H.; and Berling, J.T.: Fatigue, Tensile, and Relaxation Behavior of Stainless Steels. Mar-Test Inc., TID-26135, 1981, p. 210 .

\section{TABLE I . - CHEMICAL COMPOSITION \\ AND ROOM TEMPERATURE MATERIAL \\ PROPERTIES OF TYPE 316 \\ STAINLESS STEELa}

\begin{tabular}{|c|c|}
\hline Element & $\begin{array}{c}\text { Chemical } \\
\text { composition, } \\
\text { wt } \%\end{array}$ \\
\hline $\mathrm{C}$ & 0.04 \\
$\mathrm{Mn}$ & 1.75 \\
$\mathrm{P}$ & .030 \\
$\mathrm{~S}$ & .013 \\
$\mathrm{Si}$ & .57 \\
$\mathrm{Ni}$ & 10.20 \\
$\mathrm{Cr}$ & 17.70 \\
$\mathrm{Mo}$ & 2.08 \\
$\mathrm{Co}$ & .19 \\
$\mathrm{Cu}$ & .28 \\
$\mathrm{~N}$ & .067 \\
$\mathrm{Fe}$ & Balance \\
\hline
\end{tabular}

\footnotetext{
Yield strength, $\sigma_{\mathrm{y}}, \mathrm{MPa} . . .520$

Ultimate tensile strength, $\sigma_{\text {uts }}$, $\mathrm{MPa}$. . . . . . . . . . . 660

Elongation, percent . . . . . . . . 44

Reduction in area, percent . . . . . 78

Hardness, BHN . . . . . . . . . . . . 210

aThe material was held at $1038{ }^{\circ} \mathrm{C}$ for a sufficient time to dissolve precipitated carbides and then quenched in water to approximately room temperature.
} 


\begin{tabular}{|c|c|c|}
\hline 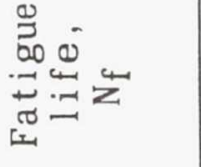 & \multirow{6}{*}{ 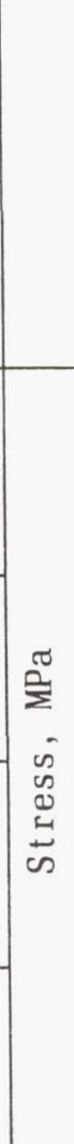 } & 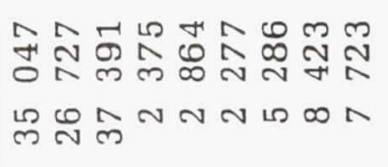 \\
\hline 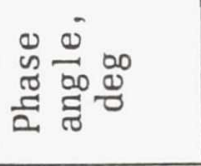 & & 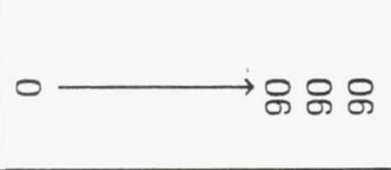 \\
\hline 䠌 & & 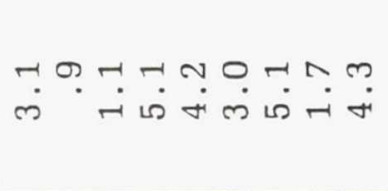 \\
\hline 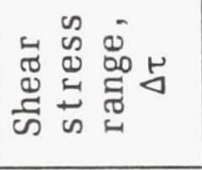 & & 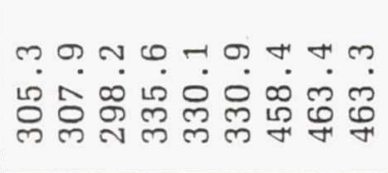 \\
\hline 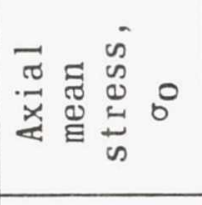 & & 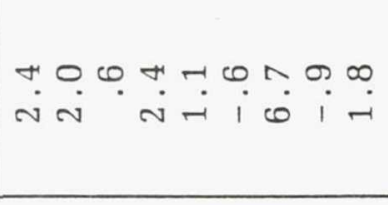 \\
\hline 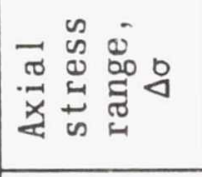 & & 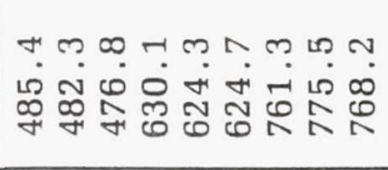 \\
\hline 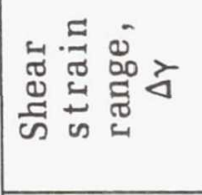 & & 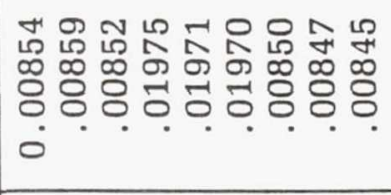 \\
\hline 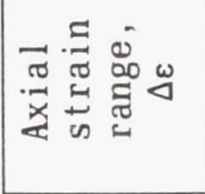 & & 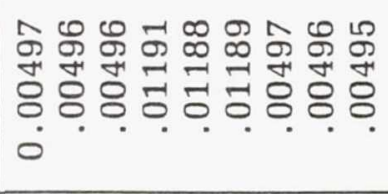 \\
\hline 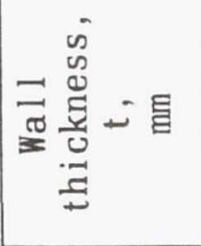 & & 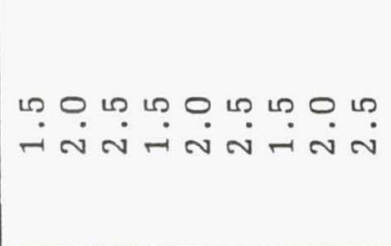 \\
\hline 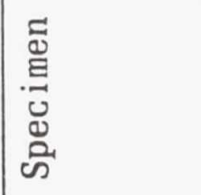 & & 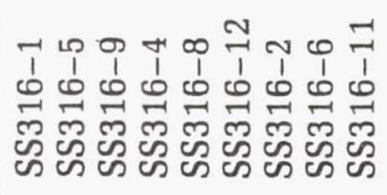 \\
\hline
\end{tabular}




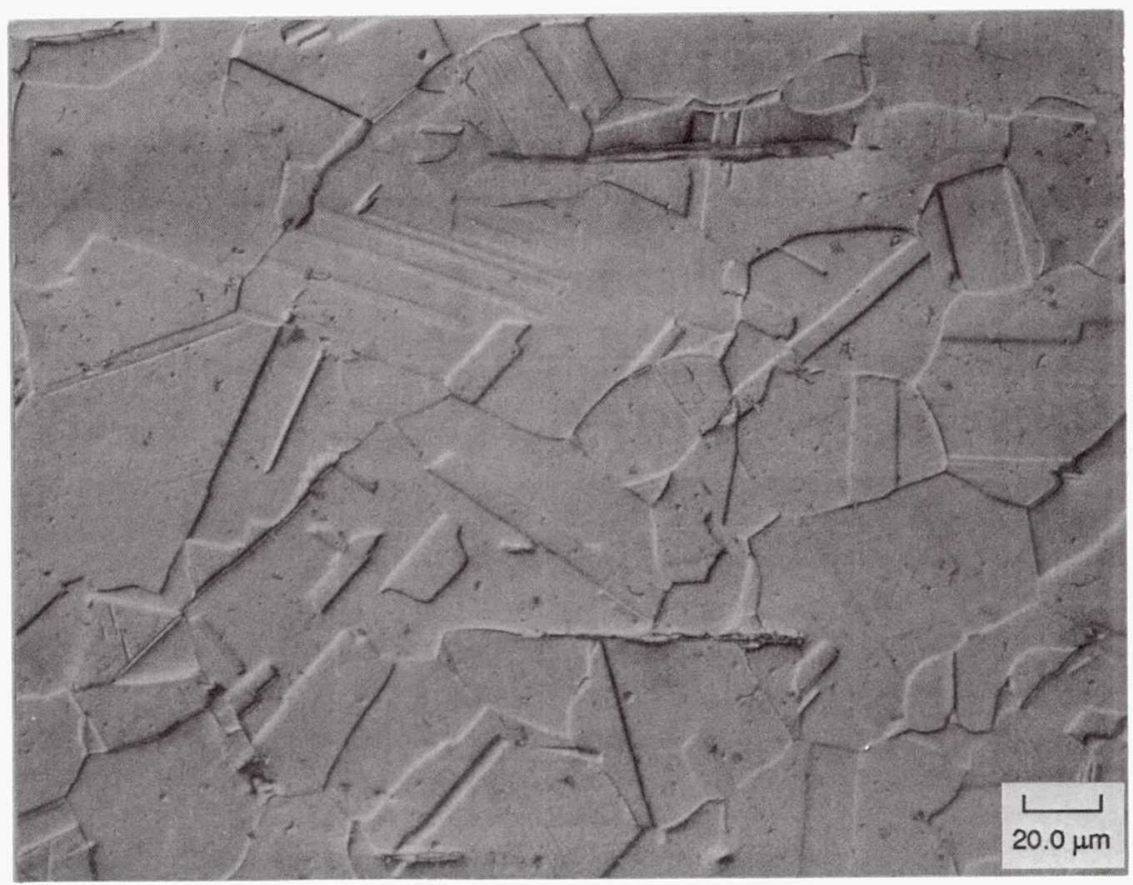

Figure 1.-Microstructure of as-received type 316 stainless steel. 


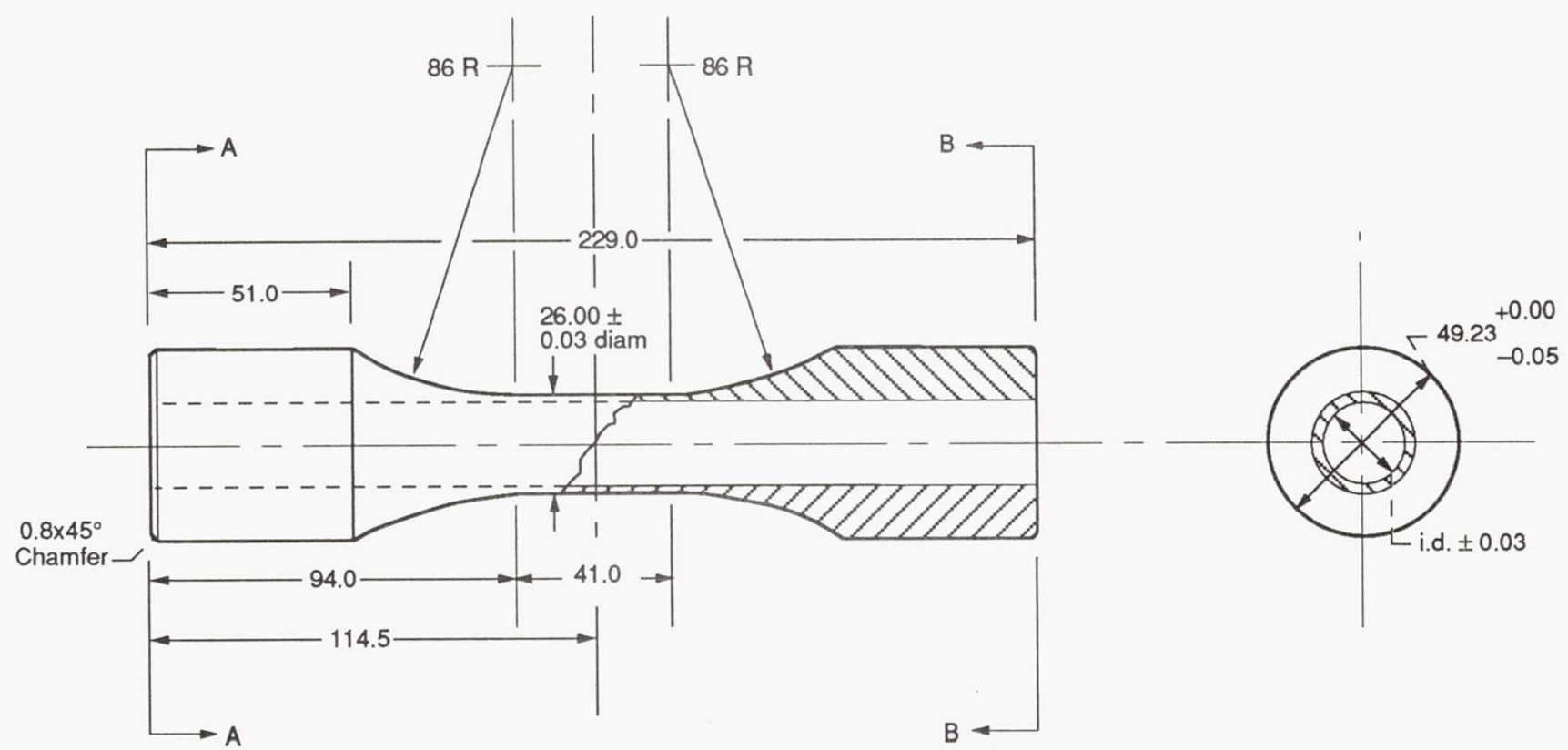

(a) Specimen drawing. (All dimensions are in millimeters.)

\section{INSTRUCTIONS FOR MACHINING NASA LEWIS AXIAL-TORSIONAL SPECIMENS}

[Material, 316 stainless steel.]

1. Use the material supplied by the requester; no substitution is allowed. Return the unused material to the requester.

2. Use tolerances of $\pm 250 \mu \mathrm{m}$ unless specified otherwise.

3. Finish the specimen inside diameter by honing. The specimen inner surface should have a finish of $0.2 \mu \mathrm{m}$ or better. All other surfaces should have a finish of $0.4 \mu \mathrm{m}$ or better.

4. Make all the diameters concentric with the longitudinal axis within $\pm 25 \mu \mathrm{m}$ TIR.

5. Make surfaces $A A$ and $B B$ perpendicular to the longitudinal axis within $\pm 125 \mu \mathrm{m}$ TIR.

6. Blend all radii with no undercuts or steps.

7. Remove final stock with a series of light cuts to minimize work hardening.

8. Mark the specimen numbers on surface AA as follows: "SS316_\#", where \# is the serial number $(1-12)$ of the specimen.

\section{NUMBER OF SPECIMENS REQUIRED}

Three different sets of specimens are required. Each set has a different nominal inside diameter. All other dimensions are the same for these three sets of specimens.

\begin{tabular}{|c|c|c|}
\hline Set & $\begin{array}{c}\text { Nominal } \\
\text { inside diameter, } \\
\mathrm{mm}\end{array}$ & Quantity \\
\hline 1 & 23.00 & 4 \\
2 & 22.00 & 4 \\
3 & 21.00 & 4 \\
\hline \multicolumn{2}{|c|}{ Total number of specimens required } & 12 \\
\hline
\end{tabular}

(b) Specifications.

Figure 2.-Axial-torsional fatigue test specimen. 


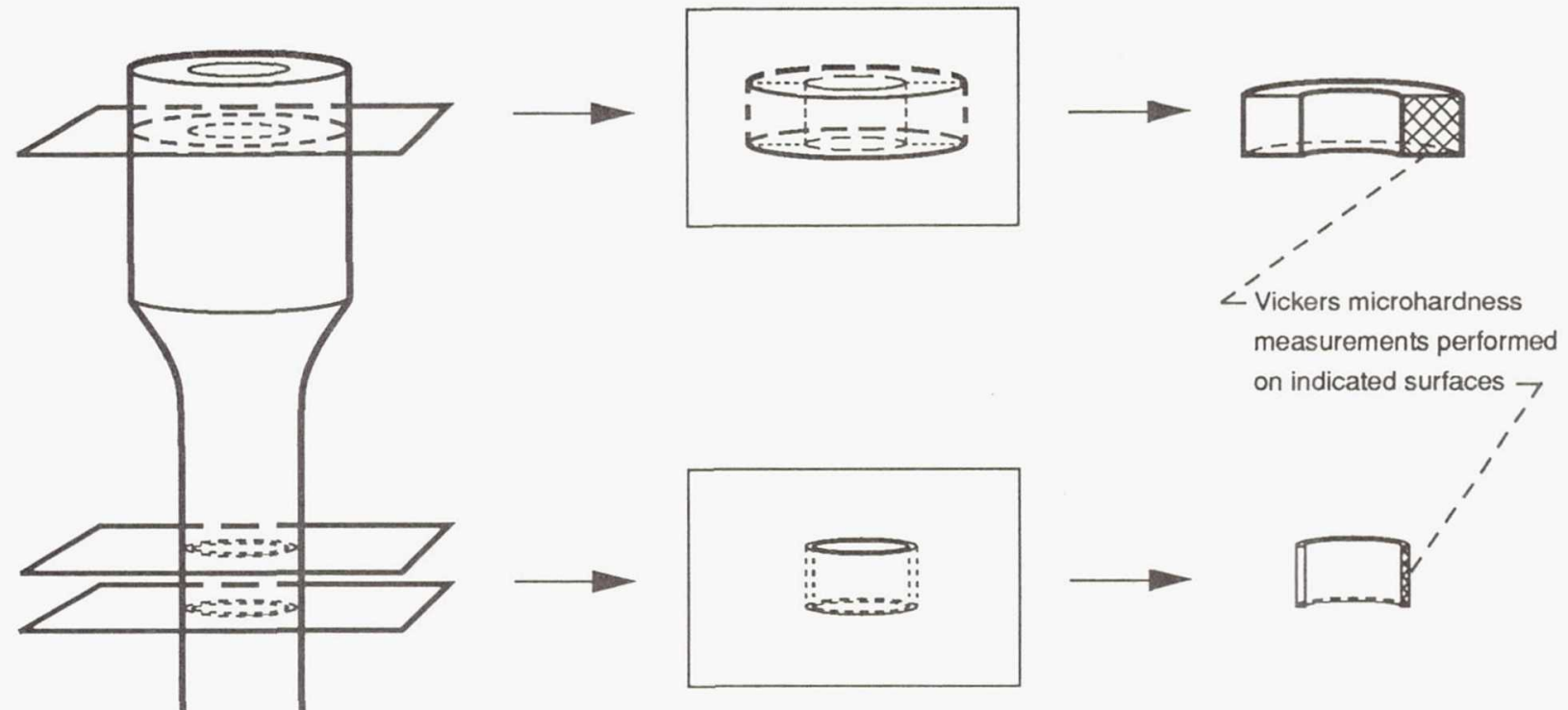

Figure 3.- Schematic of specimen sectioning plaǹ.

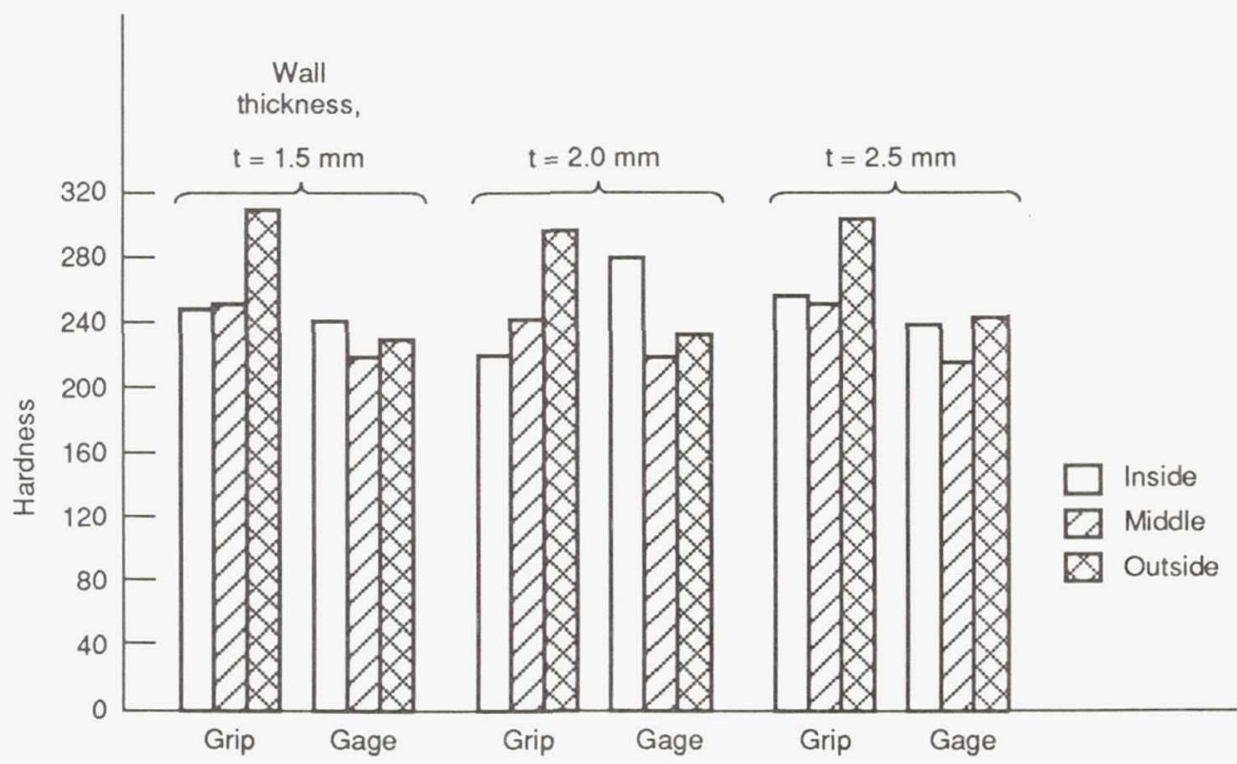

Figure 4.-Average Vickers microhardness of 316 stainless steel specimens taken at several locations. 

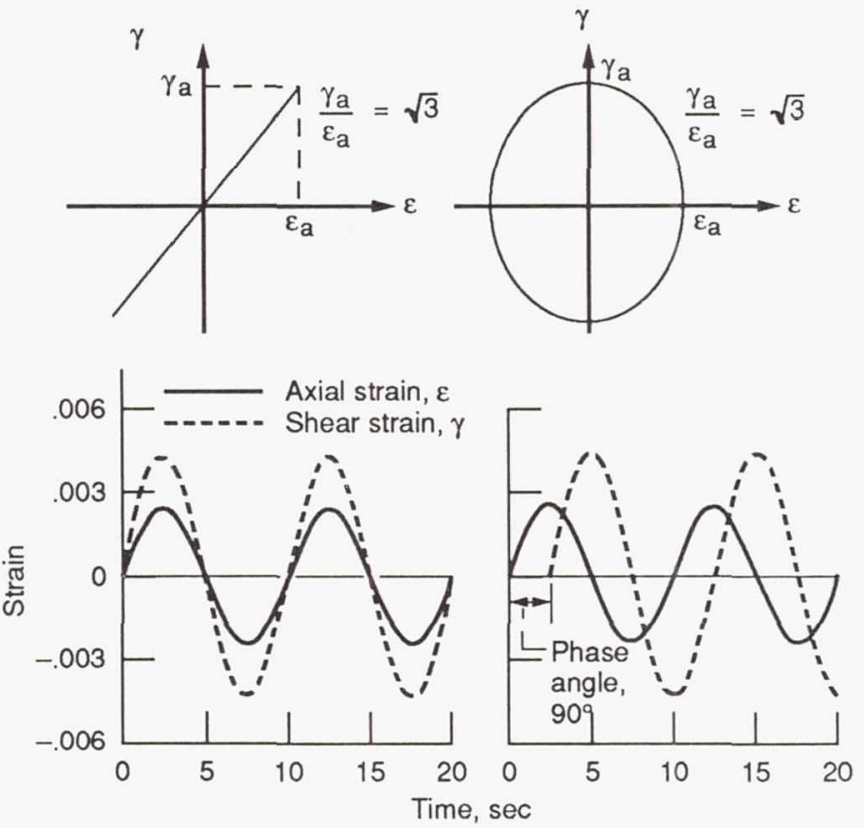

(a) In-phase loading.

(b) Out-of-phase loading

Figure 5.-Command waveforms for in- and out-of-phase axial-torsional tests.

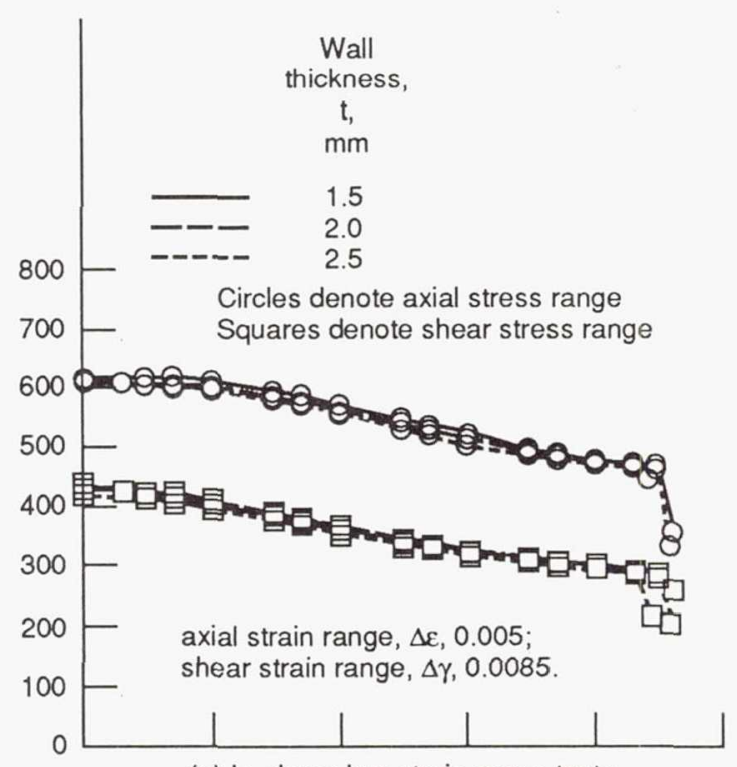

(a) In-phase low-strain-range tests.

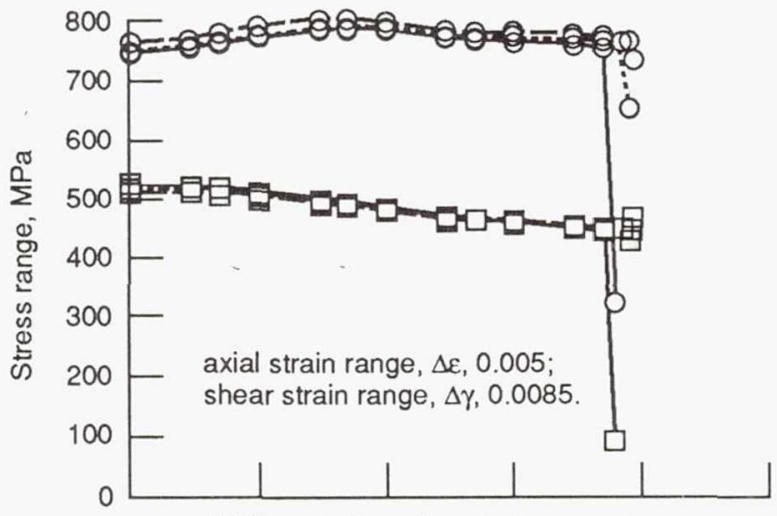

(b) Out-of-phase low-strain-range tests.

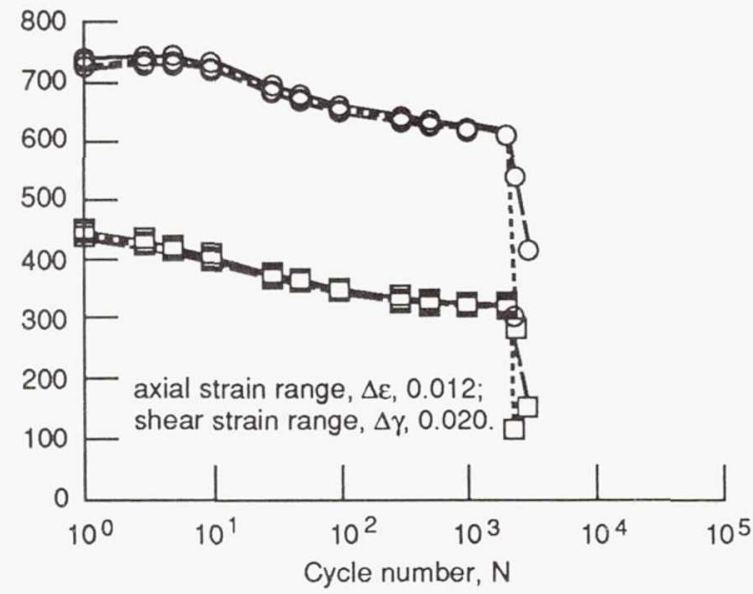

(c) In-phase high-strain-range tests.

Figure 6.- Cyclic stress response of type 316 stainless steel under axial-torsional fatigue. 

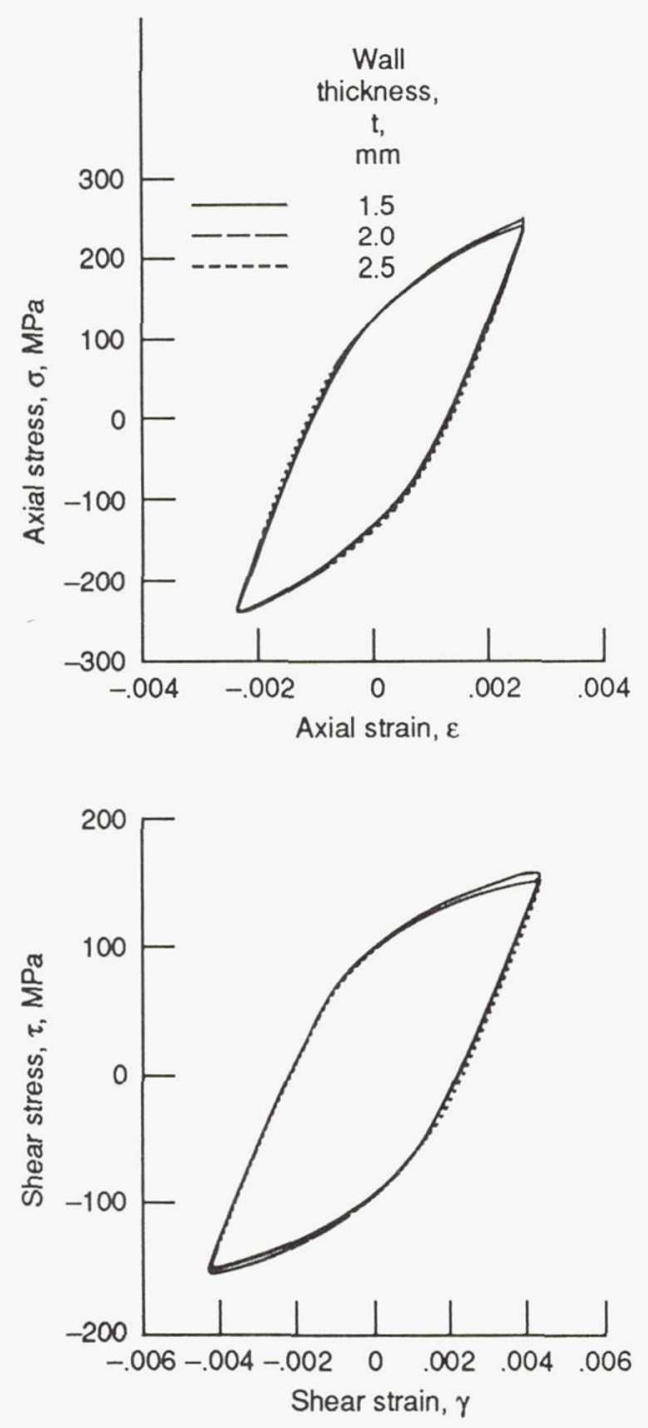

(a) In-phase, low-strain-range, axialtorsional fatigue tests; cycle 5000 .

Figure 7.-Axial and torsional hysteresis loops of type 316 stainless steel.
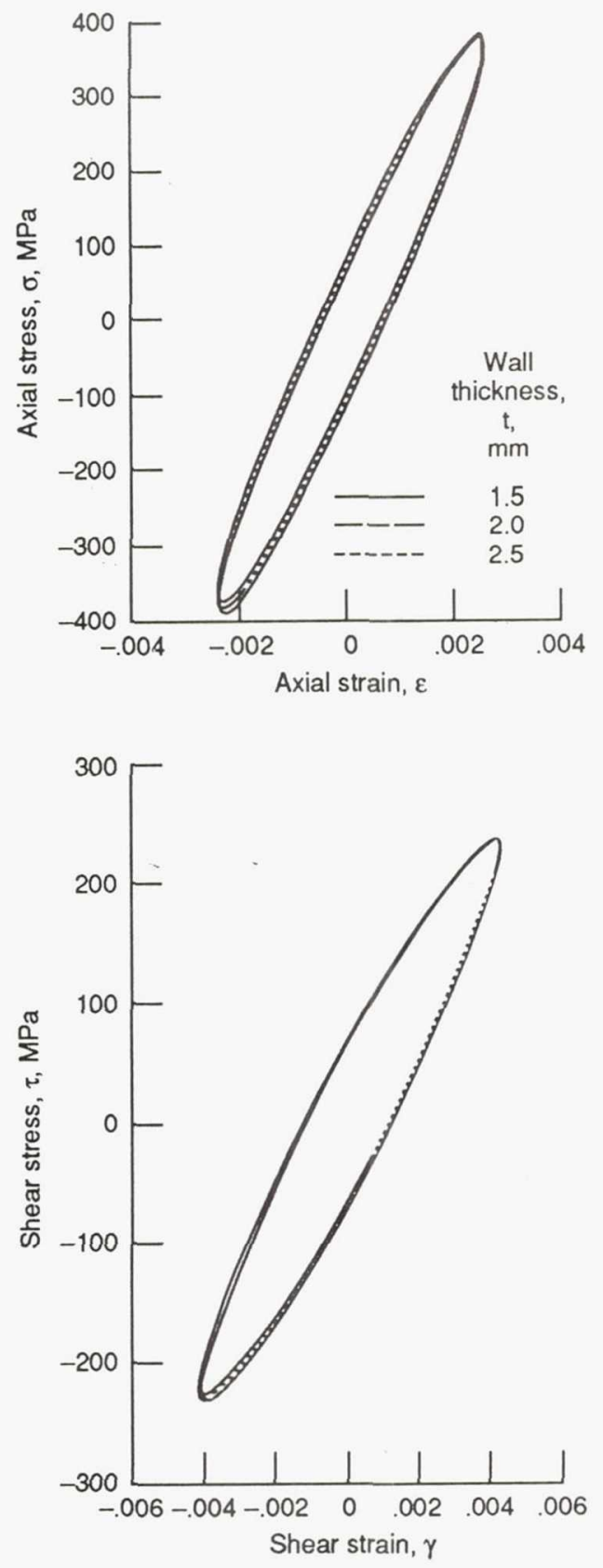

(b) Out-of-phase, low-strain-range, axialtorsional fatigue tests; cycle 1000.

Figure 7.-Continued. 

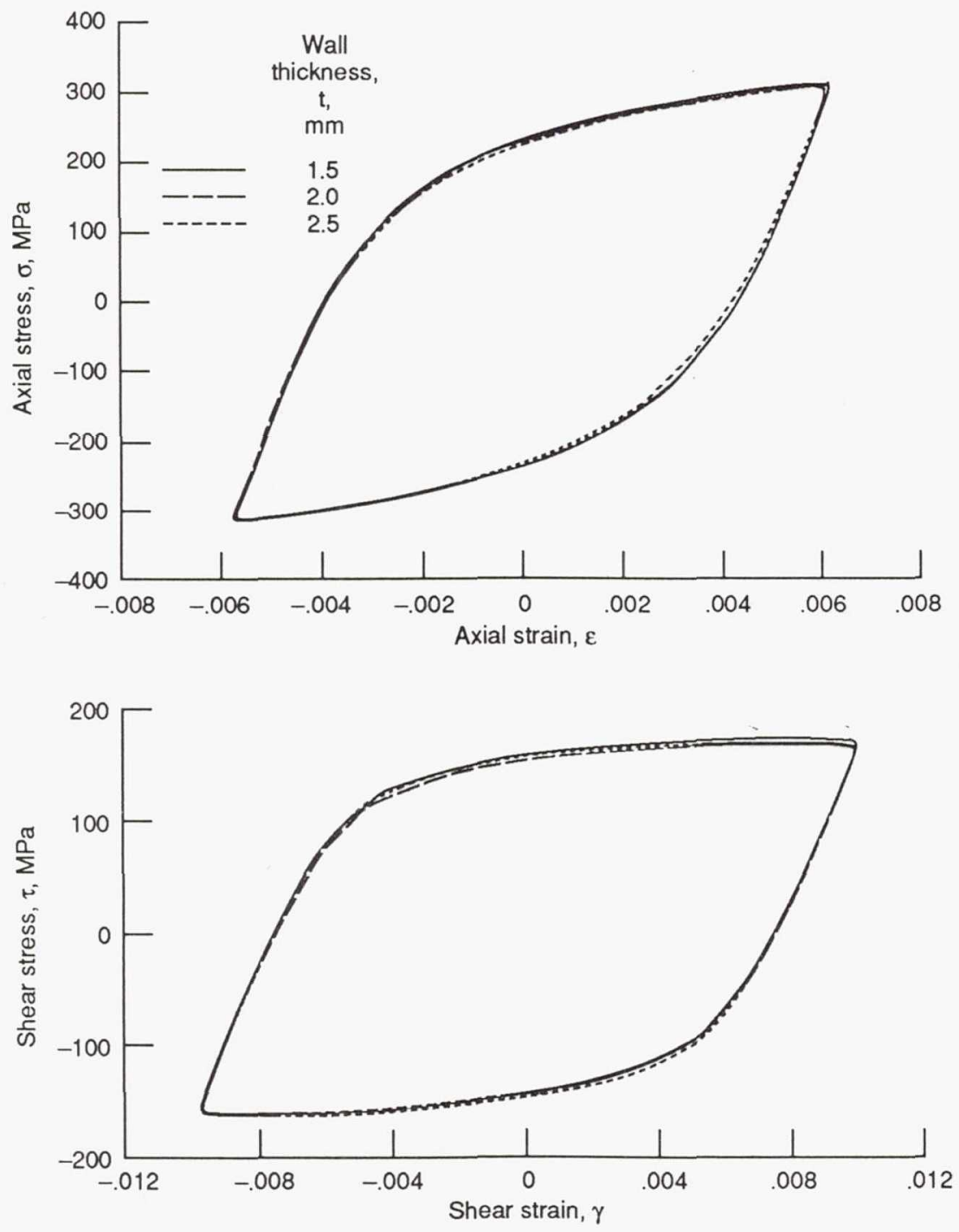

(c) In-phase, high-strain-range, axial-torsional fatigue tests; cycle 500.

Figure 7.-Concluded. 


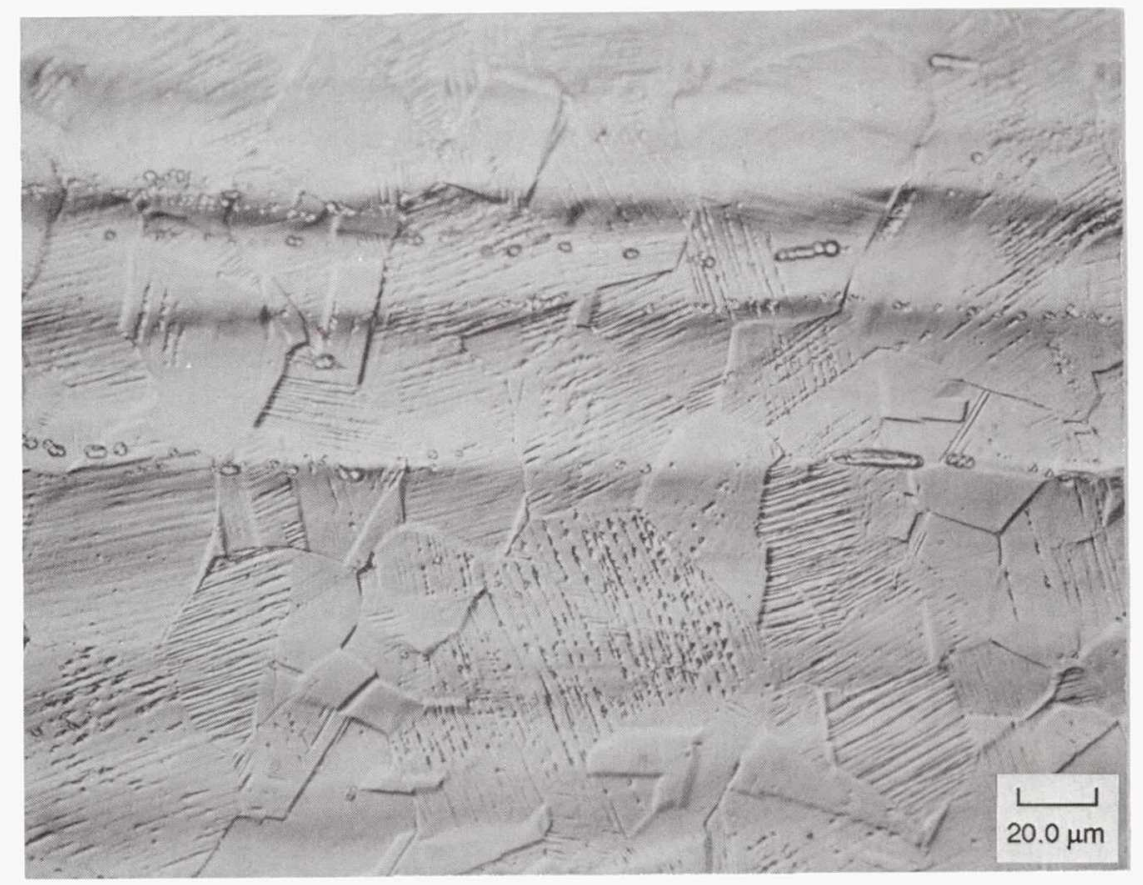

Figure 8.-Surface grains of a type 316 stainless steel specimen tested under in-phase axial-torsional loading. Axial strain range, $\Delta \varepsilon, 0.00497$; shear strain range, $\Delta \gamma, 0.00854$; fatigue life, $N_{f}, 35047$ cycles.

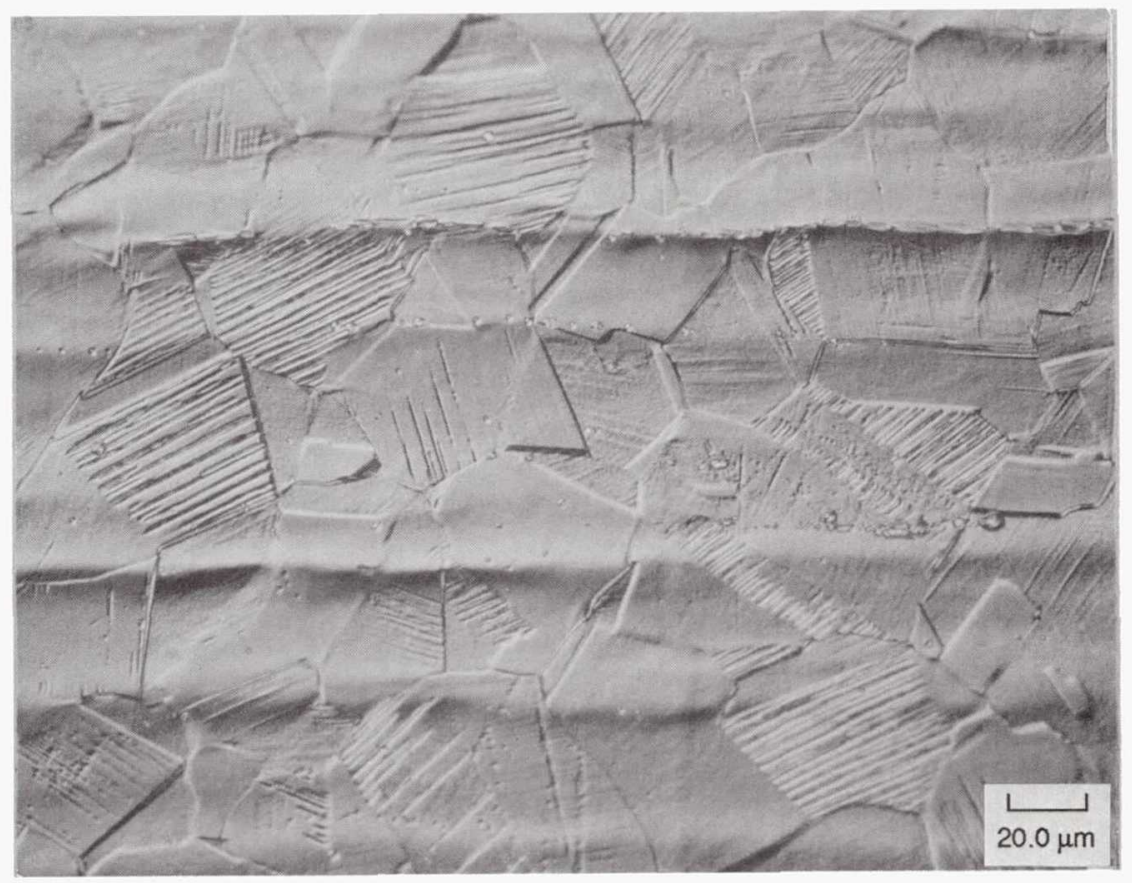

Figure 9.-Surface grains of a type 316 stainless steel specimen tested under out-of-phase axial-torsional loading. Axial strain range, $\Delta \varepsilon, 0.00497$; shear strain range, $\Delta \gamma, 0.00850$; fatigue life, $N_{f}, 5286$ cycles. 


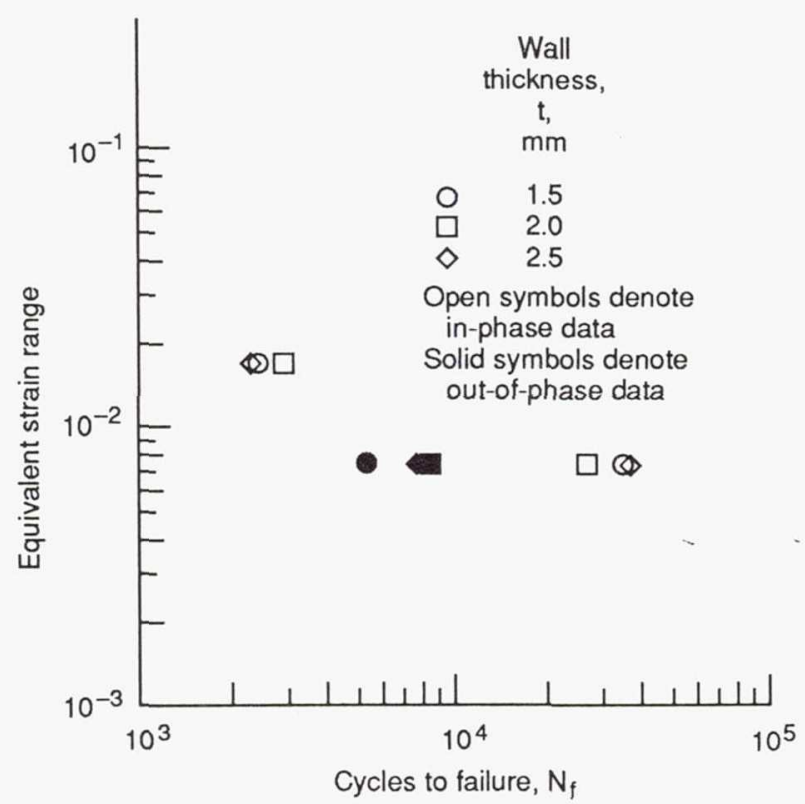

Figure 10.-Fatigue lives from in-phase and outof-phase axial-torsional tests. 


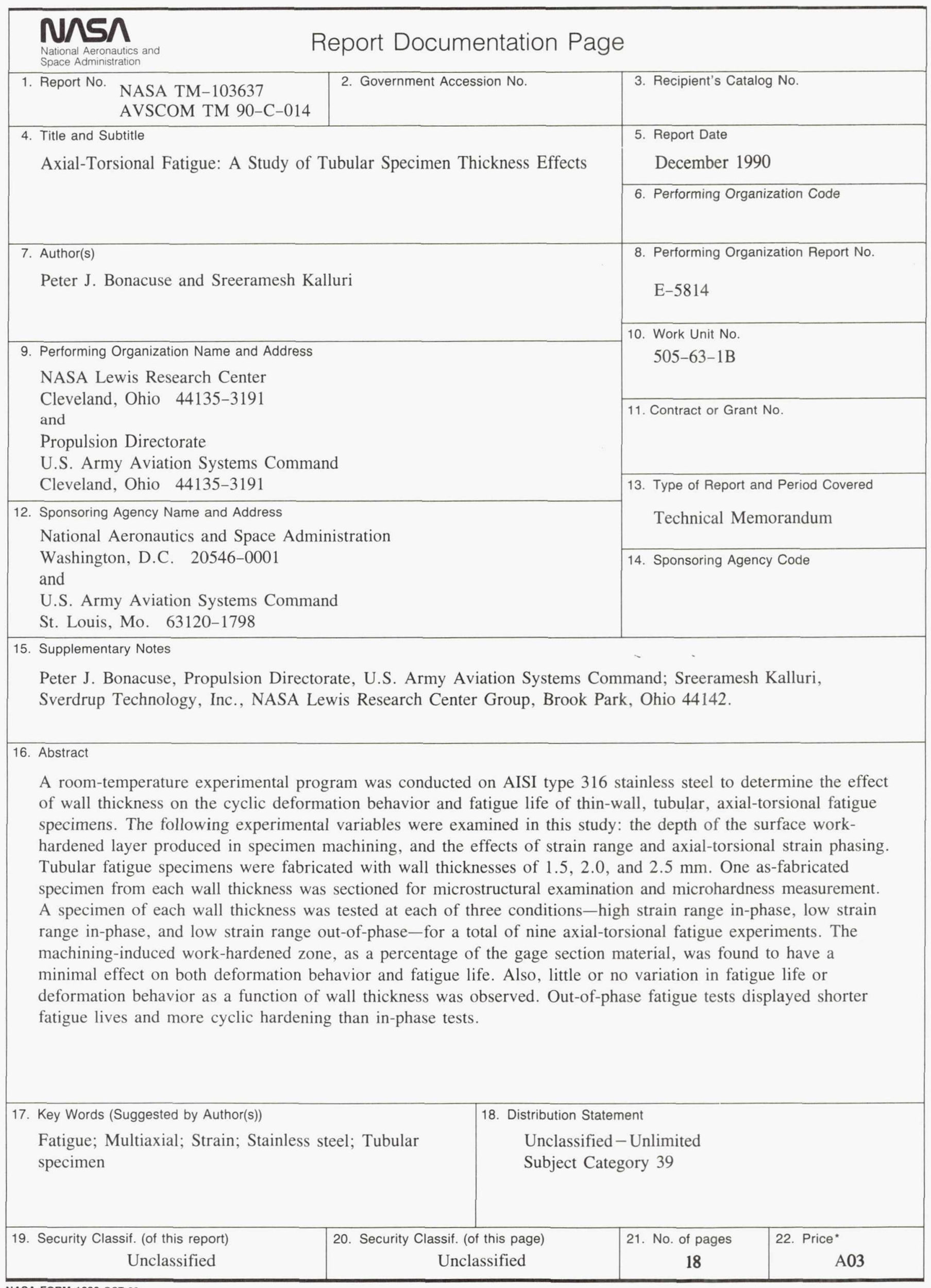

